TITLE:

\title{
Copulatory Load in a Simultaneous Hermaphrodite Aplysia kurodai Baba, 1937 (Mollusca: Opisthobranchia)
}

AUTHOR(S):

Yusa, Yoichi

\section{CITATION:}

Yusa, Yoichi. Copulatory Load in a Simultaneous Hermaphrodite Aplysia kurodai Baba, 1937 (Mollusca: Opisthobranchia). PUBLICATIONS OF THE SETO MARINE BIOLOGICAL LABORATORY 1993, 36(1-2): 79-84

ISSUE DATE:

1993-03-30

URL:

http://hdl.handle.net/2433/176221

RIGHT: 


\title{
Copulatory Load in a Simultaneous Hermaphrodite Aplysia kurodai Baba, 1937 (Mollusca: Opisthobranchia)
}

\author{
YoICHI YUSA \\ Seto Marine Biological Laboratory, Kyoto University, \\ Shirahama, Wakayama 649-22, Japan
}

With Text-figures 1-4 and Tables 1-2

\begin{abstract}
The movement of Aplysia kurodai Baba, 1937 was examined in a field population in relation to copulation. It was confirmed that the mobility of the bottom individual of a copulatory chain is curtailed simply by the total volume of the other individuals it carries (copulatory load).
\end{abstract}

Key words: Aplysia, chain copulation, copulatory load

\section{Introduction}

The sea hares of the genus Aplysia (Mollusca: Opisthobranchia) are simultaneous hermaphrodites. Copulation is usually non-reciprocal between two individuals, with one individual (acting as a male) mounting the other (female) (Eales, 1921; Carefoot, 1987). When more than two individuals participate in mating, they often form a copulatory chain; the bottom individual acts only as a female, the topmost only as a male, and the rest both as males and as females. Thus an individual that is acting only as a female must carry at least its male partner, on movement, and if it leads a copulatory chain, it must carry all the other members in the chain. Hence, it may not move as readily as a non-copulating (single) individual does. The mobility of such a female-acting individual may become more limited as the total volume of the other individuals it carries (copulatory load) increases.

In this paper a negative relationship between the distance moved and copulatory load is shown in a field population of Aplysia kurodai Baba, 1937. Since the limitation of mobility due to copulatory load is not the sole possible explanation of this relationship, other hypotheses are also tested against the results. The "copulatory chain" is also used in this paper when only two partners are engaged in copulation.

\section{Materials and Methods}

Two tide pools adjacent to each other were selected for observation in the mid-intertidal zone near the Seto Marine Biological Laboratory ( $33^{\circ} 41^{\prime} \mathrm{N}, 135^{\circ} 20^{\prime} \mathrm{E}$ ). All A. kurodai found in the pools were individually tagged, and their location in the study area and their copulatory state (not copulating; acting as a male and/or female) were noted at every 1 or $2 \mathrm{hr}$ from 12th to 15th May, 1989, when they were actively breeding. Of 26 individuals tagged, four lost their tags during the period.

Publ. Seto Mar. Biol. Lab., 36(1/2), 79-84, 1993. (Article 4) 
These four individuals were excluded from the analyses in which individual identification was indispensable.

The body volume of individuals was measured by water displacement, before and after the observation period, and the mean of the two values was used to designate their body size. For five individuals that were missing on the second measurement, the corresponding size was calculated from the first measurement and the average growth rate of the other individuals.

An individual was assumed to be single during an observation interval only when it was not copulating in both observations delimiting the interval. Similarly, an individual was considered to be at the bottom of a copulatory chain and acting only as a female when it was witnessed to be so in consecutive observations.

The distance of movement was read from maps of recorded locations for each single or femaleacting individual at each $2 \mathrm{hr}$ interval. The copulatoty load of an individual was represented by the total body volume of the individuals it carried, being 0 for single individuals. When the load at the beginning and at the end of a $2 \mathrm{hr}$ interval differed, the mean was adopted. The number of conspecifics an individual carried was also averaged if it differed at the beginning and at the end of an interval.

All the statistical analyses conducted in this paper are non-parametric two-tailed tests (Sokal \& Rohlf, 1981).

\section{Results and Discussion}

Copulatory chains observed in this population involved from two to six individuals (Fig. 1): accordingly the maximum number of individuals carried by the bottom individual of a chain was five. On the whole, the individuals in the population spent about half of their time singly, and as the copulatory chains increased in length they became progressively rarer.

There was a clear relationship between copulatory load and the distance of movement (Fig. 2). When comparison was made between four groups with different loads $(0,<50,<100, \geq 100 \mathrm{ml})$, the distance moved was significantly shorter in the groups with heavier loads $(\mathrm{P}<0.001$; Kruskal-Wallis test). The difference was significant between the groups 0 and $<50(\mathrm{P}=0.039$; Mann-Whitney U-test $)$ and between $<100$ and $\geq 100(P=0.037)$, though no difference was shown between the

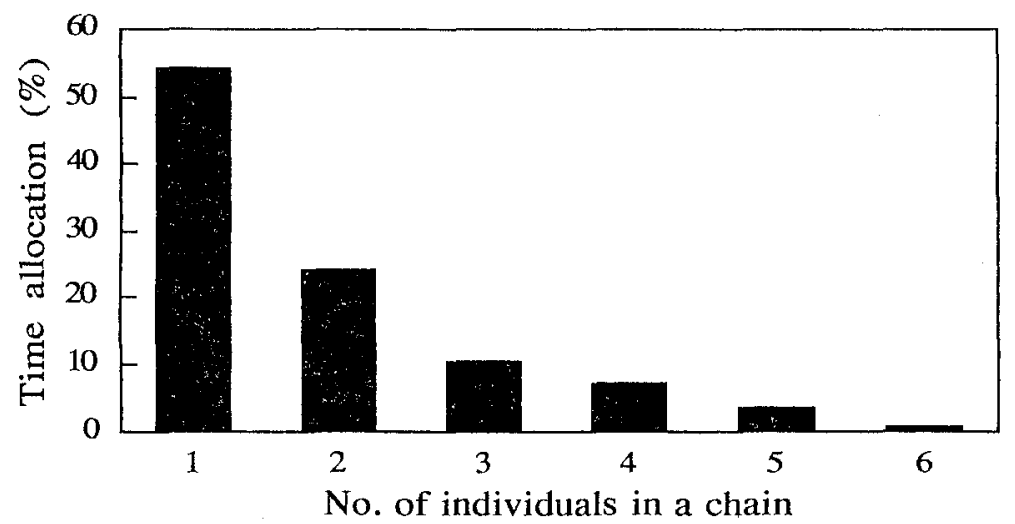

Fig. 1. Allocation of time (\%) spent as single individuals or in copulatory chains of various lengths during the observation period. Data for all the 26 individuals in the study area were included. 
groups $<50$ and $<100(\mathrm{P}=1)$.

This relationship between copulatory load and the distance of movement can be interpreted in three ways. First, copulatory load may limit the mobility of the bottom individual in a chain (copulatory load hypothesis). Its effect will be larger when the load is heavier. Secondly, if individuals move at least partly to find an appropriate copulatory partner, already copulating individuals need not search for another partner for the same copulatory role and hence may be "satisfied" in moving a shorter distance than single ones (satisfaction hypothesis). In particular, if individuals prefer the female role to the male role as suggested for opisthobranchs (Leonard \& Lukowiak, 1984; Leonard, 1991), bottom individuals, acting as females, will not search for partners intensively to act as males. Thirdly, if there is an inverse relationship between daily copulatory and crawling activities of individuals, all individuals, irrespective of their copulatory state, do not move so much during a given period of the day when the copulatory activity in the population is high (daily activity hypothesis). These three hypotheses are considered below.

First, the relationship between the number of individuals carried and the distance of movement is considered. Under the satisfaction hypothesis, the distance of movement should be smaller for female-acting individuals carrying one individual than for single individuals, but the distance should be similar among female-acting individuals carrying one individual or more, since the degree of satisfaction should not differ whether their male partners are copulating with another individual or not. On the contrary, both the copulatory load hypothesis and the daily activity hypothesis predict that the distance moved should be shorter for bottom female-acting individuals carrying more individuals, since under the former hypothesis the load will

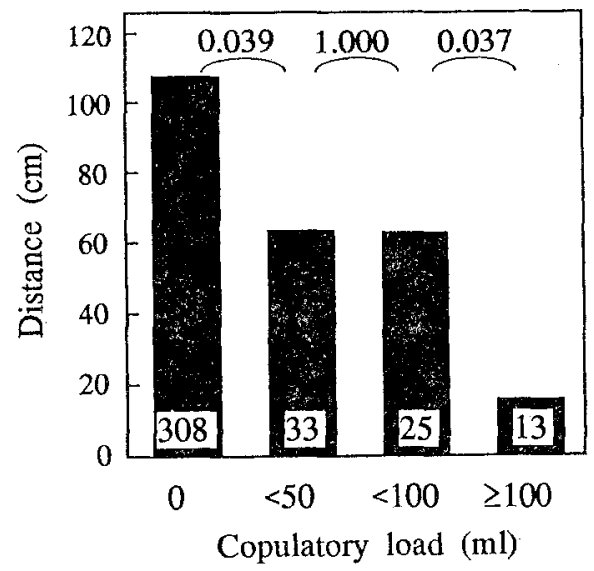

Fig. 2

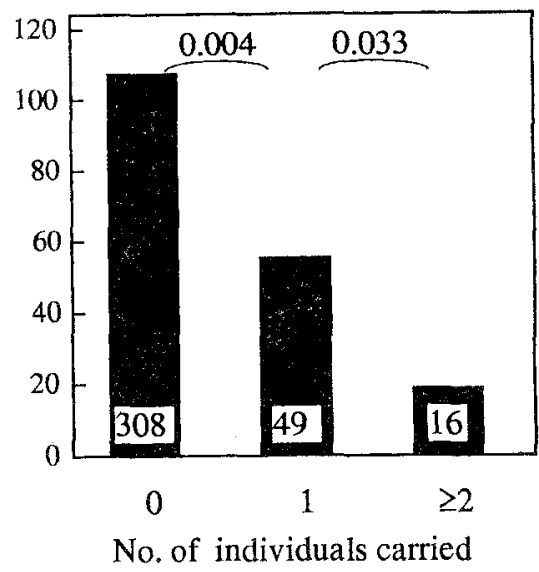

Fig. 3

Fig. 2. Copulatory load and the average distance of movement in 2 hr. Numbers in bars indicate available data sizes. Significance levels above brackets.

Fig. 3. Number of individuals carried by an individual and the average distance of movement in $2 \mathrm{hr}$. The data for the average number of 1.5 were excluded. Numbers in bars indicate available data sizes. Significance levels above brackets. 
also increase accordingly and under the latter the crawling activity will decline when copulatory activity is higher, i.e. when copulatory chains are longer. The results are shown in Fig. 3. When comparison was made between three groups with bottom individuals carrying different numbers of conspecifics $(0,1, \geq 2$; the average number of 1.5 was excluded for the critical test), the distance moved was shorter in the groups with larger numbers of individuals $(\mathrm{P}<0.001$; Kruskal-Wallis test). The difference was significant not only between groups 0 (single) and 1 (carrying only the male partner; $\mathrm{P}=0.004$; Mann-Whitney $\mathrm{U}$-test), but also between groups 1 and $\geq 2(P=0.033)$, a result that is not explicable by the satisfaction alone. Clearly, at least one of the other two mechanisms is indispensable.

The daily activity hypothesis claims an inverse relationship between copulatory and crawling activities. Although such an inverse relationship is expected if individuals show a daily copulatory rhythm and copulating individuals are less mobile than single ones, the crawling activity rhythm of individuals as a basis for this hypothesis must be independent of the daily copulatory rhythm. The crawling activity was hence investigated only in single individuals. Copulatory activity, exemplified as copulation rate, changed daily, and was high in the early morning and low in the afternoon (Fig. 4). On the other hand, the crawling activity of single individuals, exemplified as their average distance moved in each $2 \mathrm{hr}$ interval, showed a less clear but opposite pattern. There was a weak but significant inverse relationship between copulatory and crawling activities $(\mathrm{N}=36, \tau=-0.250, \mathrm{P}=0.035$; Kendall's rank correlation).

A critical test for distinguishing copulatory load and daily activity is the comparison of the average distances of movement in single and female-acting individuals within each observation interval. According to the copulatory load hypothesis, the distance moved by female-acting individuals should be shorter than that of single individuals even within each interval, while according to the daily activity hypothe-

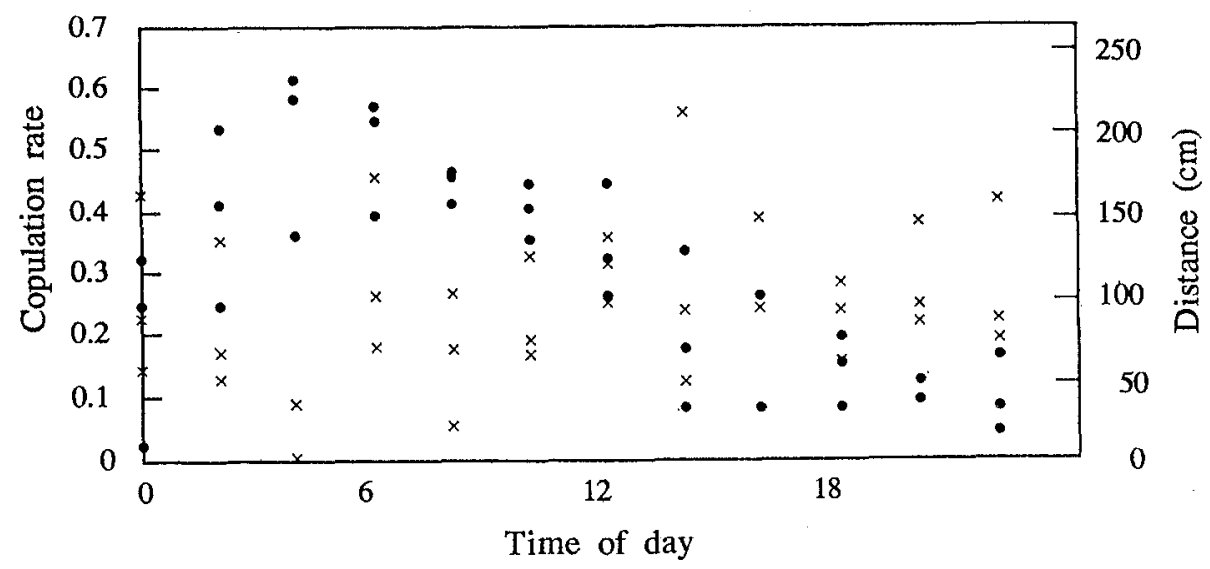

Fig. 4. Daily changes in copulation rate $(\cdot)$ and in the crawling activity (average distance moved per $2 \mathrm{hr}$ ) of single individuals $(x)$. Copulation rate was expressed as the mean number of copulations per individual in two consecutive observations between which the distance moved was obtained. 
sis these distances should be similar, since both copulatory and crawling activities are time-dependent. The results were consistent with the load hypothesis but not with the activity hypothesis (Table 1). In 21 out of 28 observation intervals within

Table 1. Comparison of the average distance of movement between single individuals and female-acting individuals within each observation interval.

\begin{tabular}{ccccc}
\hline \multicolumn{2}{c}{ No. of intervals in which } & & Total & P \\
\hline Single moved less & Female-acting moved less & & \\
\hline 7 & 21 & 28 & 0.013 \\
\hline
\end{tabular}

which the distances moved by both single and female-acting individuals were obtained, the average distance moved by female-acting individuals was shorter than that by single individuals $(\mathrm{P}=0.013$; sign test $)$. Since the copulatory load hypothesis can explain all the results discussed above while the other two hypotheses can explain them partly, the former is the most favourable explanation of the difference of movement among individuals with various loads.

The limitation of mobility of individuals due to copulatory load may affect their subsequent mating opportunity as males. Since in Aplysia it is generally the future "male" that approaches its prospective partner (Leonard \& Lukowiak, 1983; Susswein et al., 1984; Carefoot, 1987; Pennings, 1991), less mobile female-acting individuals may be less successful in acting as males to obtain preferable female partners than single ones. Two pieces of evidence showing this expectation were obtained in this population: (1) female-acting individuals mated with smaller female partners relative to themselves, compared with single individuals (Table 2; $\mathrm{P}=0.020 ;$ Mann-Whitney U-test); (2) they did not choose large female partners from available candidates (individuals within $1.5 \mathrm{~m}$ that were not already copulating as females) while single ones did (Yusa, pers. obs.).

Table 2. Comparison of the average size ratio of the female partner to the male partner between single and female-acting male partners. Copulations by four tag-lost individuals occurring within $24 \mathrm{hr}$ after the loss were excluded from the data.

\begin{tabular}{lccc}
\hline & \multicolumn{2}{c}{ Male partner } & $\mathrm{P}$ \\
\cline { 2 - 3 } & Single & Female-acting & \\
\hline $\mathrm{N}$ & 36 & 12 & \\
$\begin{array}{l}\text { female/male } \\
\text { size ratio }\end{array}$ & 1.08 & 0.75 & 0.020 \\
\hline
\end{tabular}

\section{Acknowledgements}

I wish to thank Professor Eiji Harada for his advice during the study and for critical reading of the manuscript. Drs. Keiji Wada and Graham C. Kearn made many valuable comments on the manuscript. 


\section{References}

Carefoot, T.H. 1987. Aplysia: its biology and ecology. Oceanogr. Mar. Biol. Ann. Rev., 25: 167284.

Eales, N.B. 1921. Aplysia. Liverpool Marine Biology Committee Memoirs, 24: 183-266, 7 pls.

Leonard, J.L. 1991. Sexual conflict and the mating system of simultaneously hermaphroditic gastropods. Amer. Malac. Bull., 9(1): 45-58.

Leonard J.L. \& Lukowiak, K. 1983. The behavior of Aplysia californica: Ethogram and ethological analysis of mating. Soc. Neurosci. Abstr., 9: 534.

\& —_ 1984. Male-female conflict in a simultaneous hermaphrodite resolved by sperm trading. Amer. Nat., 124: 282-286.

Pennings, S.C. 1991. Reproductive behavior of Aplysia californica Cooper: diel patterns, sexual roles and mating aggregations. J. Exp. Mar. Biol. Ecol,, 149: 249-266.

Sokal, R.S. \& Rohlf, F.J. 1981. Biometry (2nd ed.). 859 pp. W.H. Freeman and Company. New York.

Susswein, A.J., Gev, S., Achituv, Y. \& Markovich, S. 1984. Behavioral patterns of Aplysia fasciata along the Mediterranean coast of Israel. Behav. Neur. Biol., 41: 7-22. 